\title{
Simulation of process of functioning silent blocks of car suspension
}

\author{
A.I. Fedotov \\ Irkutsk National Research Technical University \\ Irkutsk, Russian Federation \\ fai.abs@yandex.ru
}

\author{
D.A. Tikhov-Tinnikov \\ East Siberia State University of Technologies and \\ Management \\ Ulan-Ude, Russian Federation \\ $\mathrm{dm} \_\mathrm{tt} @$ mail.ru
}

\author{
V.S. Baradiev \\ East Siberia State University of Technologies and Management \\ Ulan-Ude, Russian Federation \\ vsgutu-ka@mail.ru
}

\begin{abstract}
The main purpose of laboratory tests is to obtain experimental data for the development of mathematical models of the functioning of silent blocks of car suspension to develop a method of diagnosing. The object of the study is the process of functioning of the silent block of the car suspension. Methods. The tests were performed in the research laboratory of the Department cars VSGUTU. We used a stand that implements the mode of static and dynamic loading. The frequency range of the lever with the tested silent blocks was set from 0 to $1.67 \mathrm{~Hz}$. During the tests, silent blocks with different technical conditions, both new and from the failure flow of vehicles in operation, were checked. Results. Power characteristics of silent blocks of the car in a dynamic mode are received. Conclusion. The developed method of diagnosis based on the obtained experimental data will objectively determine the technical condition of silent blocks of the car suspension. Also, the application of the method in practice will significantly reduce the complexity of diagnostic work.
\end{abstract}

Keywords - suspension, silent block, experimental equipment, diagnostics, wheeled vehicle.

\section{INTRODUCTION}

Road safety of the vehicle is largely determined by the reliability of the suspension elements. In this regard, the definition of a technical condition of the suspension in operation is currently one of the urgent tasks of technical diagnostics. Any suspension of the vehicle includes a lot of details, which complicates its diagnosis, as well as requires highly qualified personnel and special equipment. Often, the detection of failures of the suspension is carried out not by diagnostic, but by the structural parameters of the technical condition, determined during disassembly and defecation of its parts. In the process of operation of the vehicle, you may also experience defects in the suspension that when driving on small and medium speeds are not perceived by the driver. This circumstance makes the detection of such defects almost impossible. When driving in more difficult conditions, such as turning at high speed, such malfunctions can lead to a sudden suspension failure. Failure of any suspension component can reduce the efficiency of operation and directly affect the active safety of the vehicle [1.2.3].

At present, wishbone suspensions are used on many passenger vehicles. A characteristic feature of lever suspensions of such type is installation of levers on silent blocks (Fig. 1).

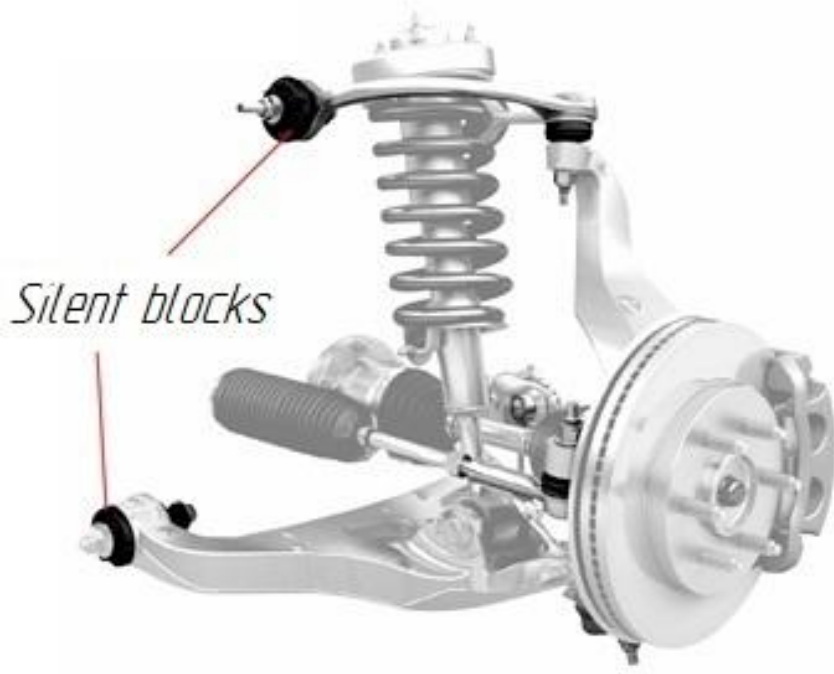

Fig. 1. Silent blocks in the wishbone suspension

Unlike other suspension elements, allowing the determination of the technical condition of organoleptic methods, silent blocks require a more thorough study, including the use of technical means of diagnosis. The characteristics of silent blocks are very sensitive to deviations that occur during their installation, as well as a violation of the rules of operation, for example, driving with high speed on the bumpy road. 
The main purpose of silent blocks-reduction of vibrations and shock loads transmitted to the body, while the design of modern silent blocks laid the impact on the suspension kinematics [4].

The silent block used in cross-arms consists of two coaxially arranged cylindrical clips, the space between which is filled with a polymer by a method of strong compression or vulcanization (Fig. 2).

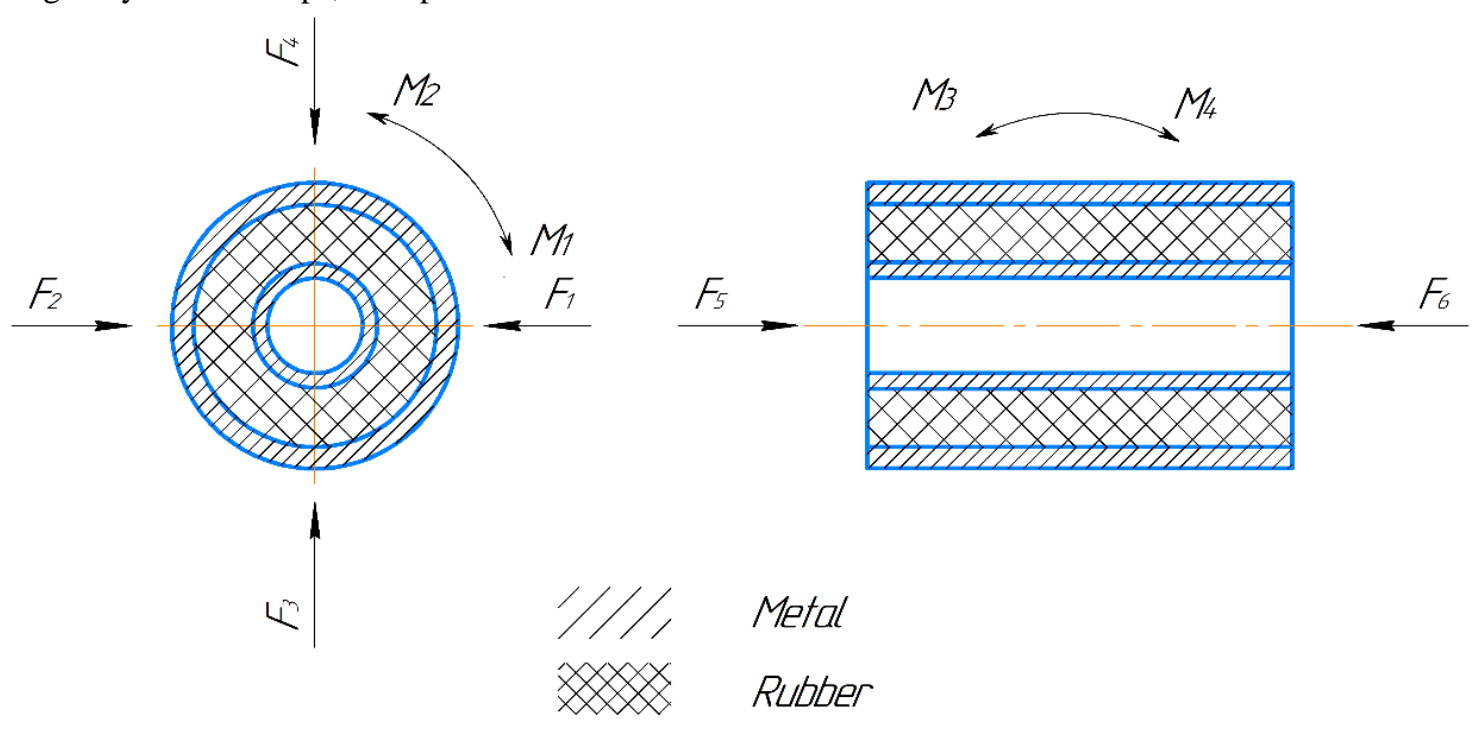

Fig. 2. Structural scheme of silent block

$\mathrm{F}_{1}-\mathrm{F}_{6}$ - forces acting on the silent block; $\mathrm{M}_{1}-\mathrm{M}_{2}$ - moments of torsion

The silent block restrains the considerable deformations acting in different planes and the directions. It was on silent block accounts for a huge share of shock loads automotive suspension. In addition, it provides radial, angular and axial compliance (Fig. 2).

During operation, the material of the silent block is subjected to relaxation as a result of which there is an axial displacement of the inner ferrule relative to the rubber material (Fig. 3). This phenomenon leads to a change in the power characteristics and kinematics of the suspension (Fig. 4), which affects the stability and controllability of the vehicle, as well as the safety of its movement.

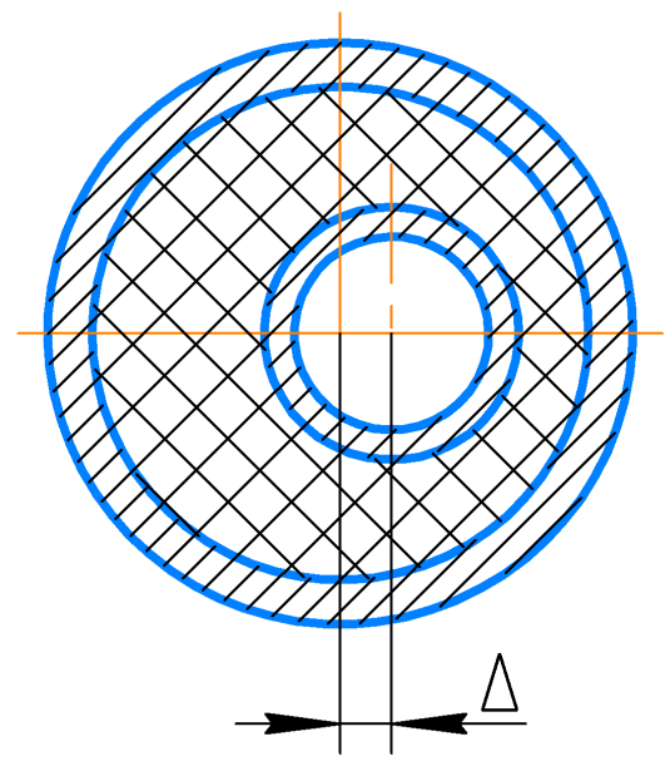

Fig. 3. Axial displacement of cage silent blocks $\Delta$ - Axial displacement 


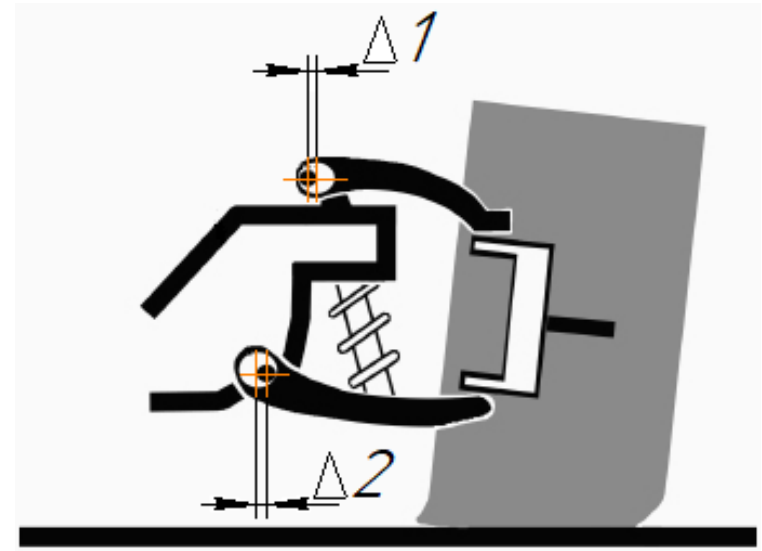

Fig. 4. Violation of suspension kinematics when changing the technical condition of suspension silent blocks

$\Delta 1, \Delta 2$ - offset of the silent blocks clip in the suspension arms

\section{THEORY}

In order to determine the technical condition of the silent blocks and to detect the future failure at an early stage, an objective method of diagnosis is required, using appropriate technological equipment $[3,5]$. Development of the method and its implementing equipment, as well as further theoretical research is based on the results of experiments aimed at obtaining empirical power characteristics of working and nonworking silent blocks..

Experimental research was carried out on a specially designed stand in the research laboratory of the Department of automobiles VSGUTU. The stand allows you to simulate the oscillation of the suspension arm, change the frequency of oscillations. The measuring system of the complex allows one to obtain experimental characteristics of the tested silent blocks [6].

The experiments were studied silent blocks brands OEM 2101-2904043 of car VAZ. To determine the power characteristics of the object with good technical condition, forty new silent blocks were tested, the experimental data of which were averaged.

Similar characteristics were obtained for objects with changed technical condition, as well as for faulty silent blocks (Fig. 5). Processes of change of force on the lever $(F, H)$ at its movement $(S, m)$ were registered.

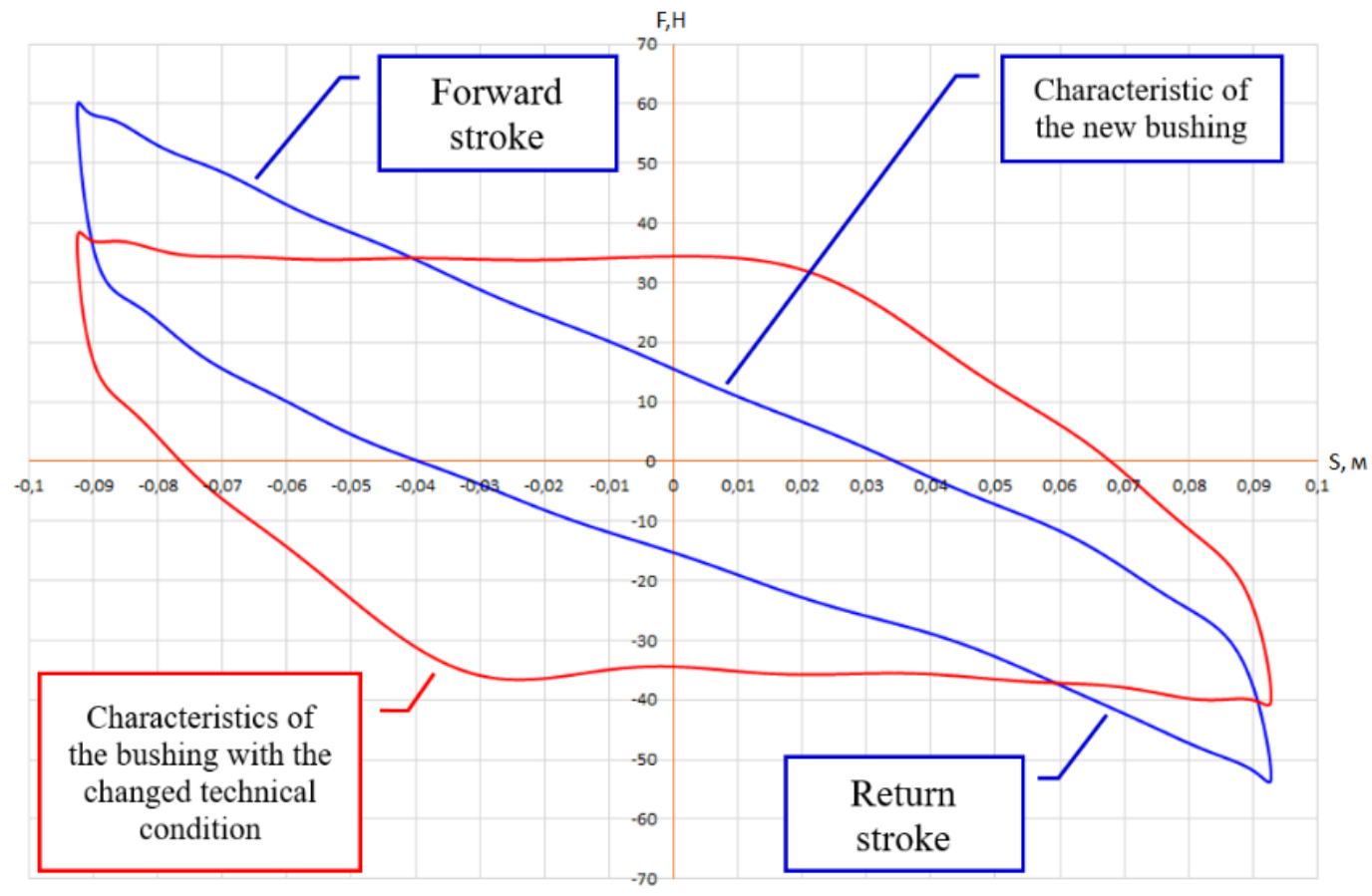

Fig. 5. The average value of the experimental data

\section{RESULTS AND DISCUSSION}

The data obtained during the processing are decomposed into Fourier series [7], which allowed one to present the experimental signal in the form of amplitude and phase spectrum. Further, using the procedure of "Fourier synthesis" for the most significant amplitudes analytical expressions to describe the average power characteristics of the tested silent blocks were obtained. To synthesize the signal travel time, 
there is about five harmonics to signal the efforts of fifteen harmonics. Signal synthesis is performed by the following expression (1):

$$
S=\frac{A_{0}}{2}+\sum_{i=1}^{n} A_{n} \cos \left(n \omega t+\varphi_{n}\right)
$$

\section{S - synthesized signal;}

A - amplitude;

$\varphi_{\mathrm{n}}-$ phase of the harmonics;

$\omega$ - frequency.

The results of the performed experimental studies are an empirical basis for the development of a mathematical model of the functioning of the silent block, in order to diagnose it. A mathematical model for describing the work of a serviceable silent block can be built on the basis of generally accepted theoretical models describing the work of polymers [8.9].

Initially, the model is based on the classic Maxwell model consisting of an elastic element and a damper that describes the change in force $F_{b}$, developed by the silent block from its deformation, according to the expression:

$$
F_{b}=C_{x} \times S_{p e x}+K_{D} \times \frac{d S_{p e x}}{d t}
$$

$$
\begin{aligned}
& \mathrm{C}_{\mathrm{x}} \text { - stiffness of the elastic element; } \\
& \mathrm{S}_{\mathrm{p} \text { ex }} \text { - deformation }[\mathrm{m}] \\
& \mathrm{K}_{\mathrm{D}} \text { - damping factor; } \\
& \mathrm{dS}_{\mathrm{p} \mathrm{ex}} / \mathrm{dt} \text { - strain rate }[\mathrm{m} / \mathrm{s}]
\end{aligned}
$$

The results of calculations using the expression (2) showed that the Maxwell model describes hysteresis arising during the work of the silent block, but the resulting characteristic has the form of a symmetric ellipse, which does not correspond to the obtained experimental characteristics that are asymmetric with respect to the central axis (Fig. 5). From the mechanics of polymers, it is known that in the case of asymmetry characteristics in the composition of the model it is necessary to introduce an additional element that characterizes the internal friction that occurs between the molecules of the elastic material. Thus, the model of a serviceable silent block can be represented as a set of three elements: elastic, damping and friction (Fig. 6)
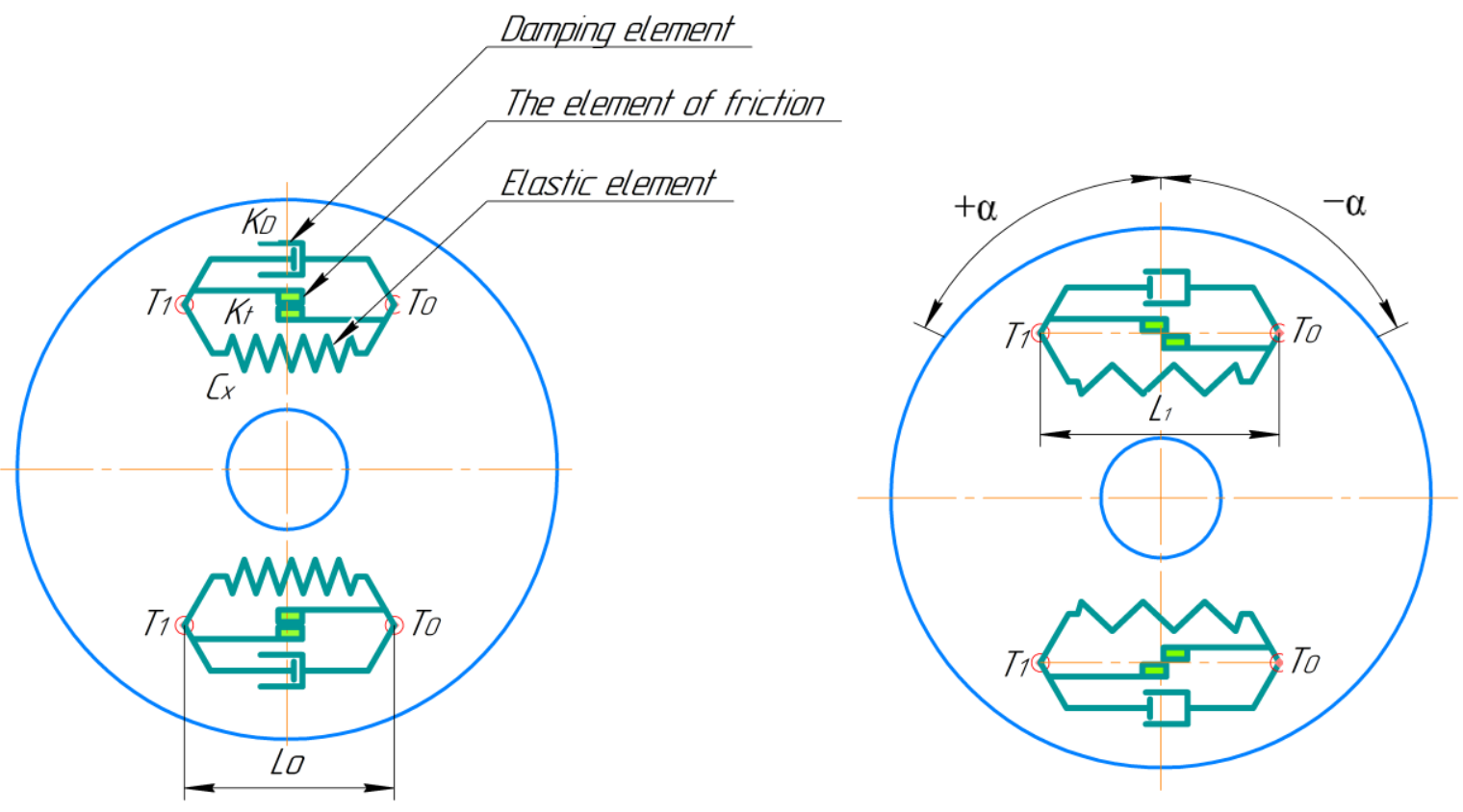

Fig. 6. The scheme of the mathematical model

In this case, the mathematical model of the silent block operation process is as follows (3):

$$
F_{b}=C_{x} \times S_{p e x}+K_{D} \times \frac{d S_{p e x}}{d t}+K_{t} \times \operatorname{sign}\left(\frac{d S_{p e x}}{d t}\right)
$$

$\mathrm{C}_{\mathrm{x}}$ - stiffness of the elastic element;

$\mathrm{S}_{\mathrm{p} \mathrm{ex}}-$ deformation $[\mathrm{m}]$;

$\mathrm{K}_{\mathrm{D}}$ - damping factor; 
$\mathrm{dS}_{\mathrm{p} \mathrm{ex}} / \mathrm{dt}-$ strain rate $[\mathrm{m} / \mathrm{s}]$

$\mathrm{K}_{\mathrm{t}}$ - friction factor;

sign - piecewise constant function.

Solving the presented equation (3), the calculated dependences of the force change on the lever $(F, H)$ during its displacement $(S, m)$ are obtained. The comparison of the obtained dependences with the experimental data (Fig. 7) shows that in this form, the model describes quite well the change of force during its movement, but there are quantitative differences between the calculation and the experiment. It should be noted that the qualitative nature of the calculated values is similar to the experimental data.

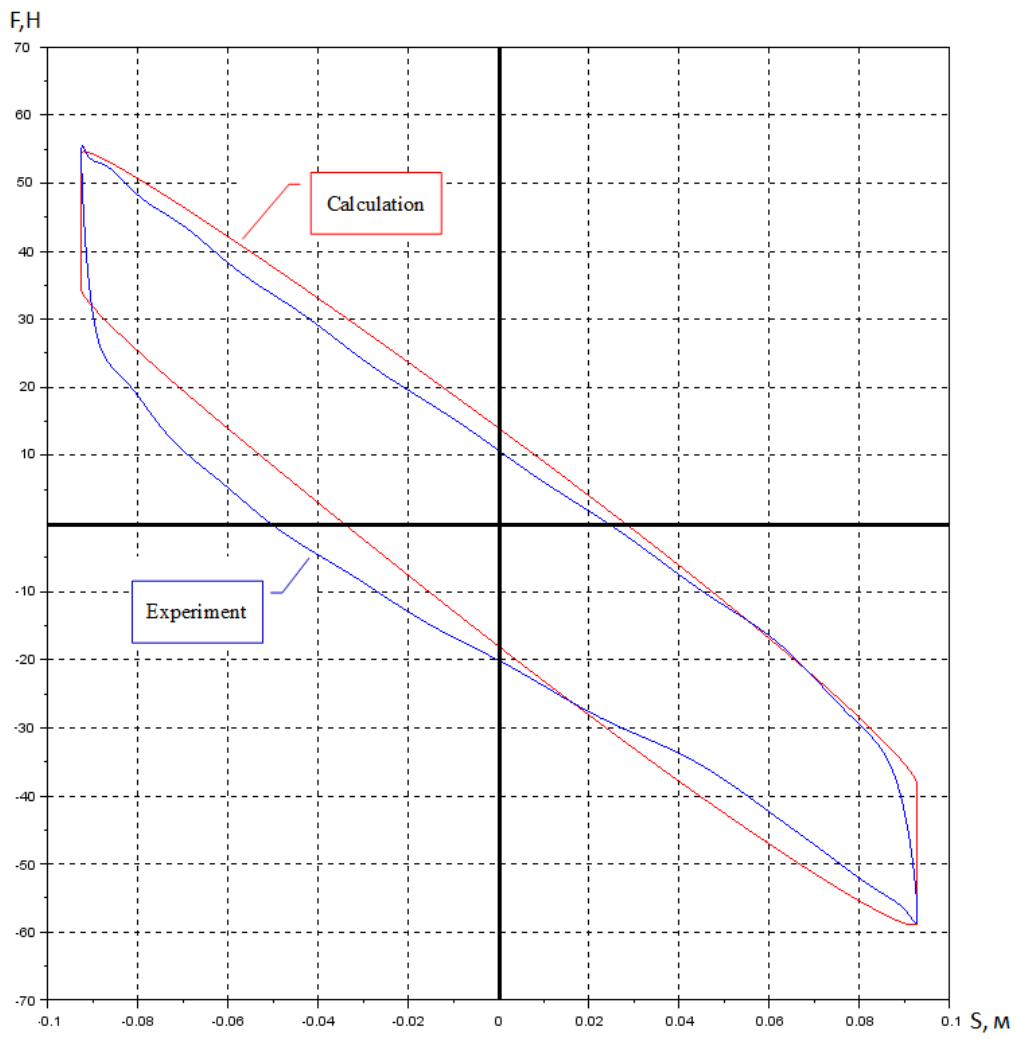

Fig. 7. Power characteristic of silent block

For a more accurate description of the experimental results using the presented model, it is necessary to determine the functions characterizing the changes in coefficients $K_{D}$ and $K_{t}$ from the polymer deformation rate $\left(\mathrm{dS}_{\mathrm{p} \text { ex }} / \mathrm{dt}\right)$. In the case of simulation of a faulty object, the model must take into account the additional friction that occurs in the places of the polymer rupture, as well as the friction between the sleeve and the elastic material of the silent block.

\section{CONCLUSION}

Thus, this mathematical model after refinement can be used to describe the operation of the silent block in the suspension of the car in the diagnostic mode, as well as to perform theoretical studies to determine the impact of the technical condition of the rubber-metal hinges suspension motor vehicle on the stability and controllability of its movement [10-12].

\section{References}

[1] A.V. Boiko, V. P. Halezov., O. S. Yan'kov, A. S. Markov, "System for measuring normal and tangential reactions distributed along the length of the contact patch of the tire with elastic flat supporting surface", The car for Siberia and the far North: the Design, operation, Economics, pp. 102-110, April 2015 [90th international scientific and technical conference of the Association of automotive engineers in the Irkutsk national research technical University, p. 482, 2015]

[2] A.I. Fedotov, A.V. Lisenko, D.A. Tihov-Tinnikov, "Control of the technical condition of the suspension of vehicles in operating conditions by the method of circular movement", The car for Siberia and the far North: the Design, operation, Economics, pp. 232-238, April 2015 [90th international scientific and technical conference of the Association of automotive engineers in the Irkutsk national research technical University, p. 482, 2015].

[3] A.I. Fedotov, Technology and organization of diagnosis in service support, 2015

[4] I.M. Ryabov, K.V. Chernyshov, A.V. Pozdeev, "Vibroprotective and Energetic Properties of Vehicle Suspension with Pendular Damping in a 
Single-Mass Oscillating System", Procedia Engineering, vol. 206, pp. 519-526, 2017.

[5] A. I. Fedotov, E. M Portnyagin, "On the question of test effects on the object of diagnosis", Vestnik of Irkutsk state technical University, Vol. 5 (52), pp. 95-100, 2011.

[6] A.I. Fedotov, D.A. Tihov-Tinnikov, V.S. Baradiev, "Equipment for experimental determination of power characteristics of automotive silent blocks", Vestnik of Irkutsk state technical University, Vol. 8 (115), pp. 176-181, 2016

[7] V.S. Baradiev, D.A. Tihov-Tinnikov, "Experimental study of power characteristics of automotive silent blocks", Safety of wheeled vehicles in operation, pp. 12-20, April 2017 [99th international scientific and technical conference of the Association of automotive engineers in the Irkutsk national research technical University, p. 570, 2017].
[8] I. I Goldberg, Mechanical behavior of polymeric materials (mathematical description), 1970.

[9] V.N. Kuleznev, Fundamentals of physics and chemistry of polymers, 1977

[10] A.I. Fedotov, D.A. Tihov-Tinnikov, N.I. Ovchinnikova, A.V. Lysenko, "Simulation of car movement along circular path", IOP Conference Series: Earth and Environmental Science, vol. 87, pp. 1-8, March 2017 [IOP Conference Series: Earth and Environmental Science, 2017].

[11] A.I. Fedotov, A. V. Boyko, Mathematical modelling of processes of functioning of vehicles, 2012.

[12] I.V. Ryabov, V.V. Novikov, A.V. Pozdeev, "Efficiency of Shock Absorber in Vehicle Suspension", Procedia Engineering, vol. 150, pp 354-362, 2016. 